\title{
Development of OntEIR Framework to Support Heritage Clients
}

Shadan Dwairi and Lamine Mahdjoubi

\section{Abstract}

Employers of heritage projects always have a main requirement, which is for the project to be completed within the time scale, budget, and with the highest quality. Evidence suggests that for clients of heritage buildings, various factors led to the unfortunate increase and out of control costs, such as poor definition of requirements and lack of capacity to engage effectively with suppliers.

Employer Information Requirements (EIR) is seen as central to deliver the Heritage BIM (HBIM) agenda. The successful and clear identification of the specifications of the employer and heritage building requirements is an important if not the most important phase in delivering successful heritage projects, and is referred to as the Employer Information Requirements (EIR). Despite the various research efforts, the specification of employer's information requirements is still underdeveloped. Indeed previous research confirmed that due to complexities in identifying and conveying accurately employers' actual needs and requirements to the heritage project's team and the immense magnitude of project information project briefings may not truly reflect employer's requirements.

This chapter reports on an ongoing study designed to support heritage clients in making informed and sound decision in defining their requirements. The aim of this research is to investigate the development of an ontology-based, BIM enabled framework for EIR. This research examines innovative approaches and methods for conveying employer information requirements (EIR) using a framework to capture, analyse, and translate these requirements based on an ontology model. This framework will enable the heritage team to capture these requirements and convert them to constructional terms understood by all stakeholders. It is the contention of this chapter that this process will save time, effort and cost, and will provide an informed basis for delivering a successful project that satisfies both the employer and the supply chain. 


\section{Introduction}

The importance of OntEIR emerges from the importance of EIRs and the fact that Building Information Modelling (BIM) was mandated by the UK government to be used in all public buildings by 2016. Employer Information Requirements (EIR) is seen central to deliver the BIM agenda. The successful and clear identification of the specifications of the client and the building requirements is an important if not the most important phase in delivering successful heritage projects, and is referred to what is called EIR

One of the key pillars of BIM (PAS 1192-2:2013, 2013) produced by the BIM Task Group proposed setting out the EIR, as part of the Employer's Requirements document, which is incorporated into tender documents. Such documents provide information that is mandatory for suppliers to be able to produce the Heritage BIM Execution Plan (HBEP), in which the proposed approach, capability and capacity can be evaluated. This information includes requirements required by the client in addition to key decision points and project stages.

EIR documents are designed to be included in the tender documents for the procurement of both the Design Team and the Constructor (Employer's Information Requirements Guidance notes, 2013). The importance of such documents is derived from being the first step in the information delivery cycle of the project, and is an important element of project BIM implementation, in addition to being the guideline for the BIM protocol implemented through the HBEP.

Figure 18.1: Impact of EIR on the construction process (adapted from Micheal Earley, bim-manager.net)

The development of EIR starts from the early stages of the project. Initially it might take a form of a simple process map which identifies the key decisions that will need to be made during the project to ensure that the solution developed satisfies the business needs and defines in very broad terms the information that will be needed to make such decisions. In the report published by the Government Construction Strategy Cabinet office (2011), it was announced that the Government's intention to require collaborative 3D BIM (with all project and asset information, documentation and data being electronic) for its projects by 2016. It should be mentioned that in the BIM plan of work, defining EIR is main phase because of its importance in setting out the information required by the employer aligned to key decision points or project stages, and thus enabling suppliers to produce and initial HBEP from which their proposed approach, capability and capacity can be evaluated 


\section{State of the art}

Refurbishment and restoration projects account for about $46 \%$ of the total construction output in the construction industry in the UK (Lee and Egbu, 2005). These kinds of projects hold higher risk and are more complex, and requires more coordination than a new built project that is why clear identification of requirements and constraints may pose a difficult task. Studies have been carried out in the field of requirements, of which clear definition is important for the success of both refurbishment projects, including restoration and heritage projects, and for new projects.

The term client, or employer will be used in this study to refer to the owner or representative of the owner of a building, who has the authority to comment or make a decision on the restoration process.

Research work is in the field of requirements, postulated by Kamara et al. (2000), advocated construction briefing as "client requirements process" within the discipline of concurrent engineering for life cycle design and construction. Bruce and Cooper (2000) highlighted the importance of understanding both hard and soft processes when developing requirements for employers. The document that contains the written instructions/requirements of the employer is referred to as the "brief" which should include the following information:

- The background, purpose, scope, content and desired outcomes of the project;

- The functions of the intended facility and the relationships between them;

- Cost and time targets, instructions on the procurement and organisation of the project;

- Site and environmental conditions, safety, interested third parties, and other factors that is likely to influence the design and construction of a facility.-(Kamara and Anumba, 2001).

Kamara et al (2002), have also described the requirements for any type of project to be:

- Client requirements: which describe the facility that satisfies his or her business need. Incorporates user requirements, those of other interest groups and the lifecycle requirements for operating, and maintaining of the facility

- Site requirements: which describe the characteristics of the site on which the facility is to be built

- Environmental requirements: which describe the immediate environment

- Regulatory requirements: which are building, planning, health and safety regulations and other legal requirements

- Design requirements: which are requirements for design, a transition of the client needs, site and environmental requirements

- Construction requirements: which are requirements for actual construction, which derive from design activity

Other models that have been implemented in this area is the Client Requirements Processing Model (CRPM), which adopts structured methods in translating the "voice of the client" into the "voice of the designer". The model has three main stages: define client requirements, analyse client requirements, and translate client requirements. These stages sub-divide further into activities and utilise appropriate information gathering tools, decision support tools and quality assessment tools (e.g. Quality Function Deployment) to develop solution neutral specifications. CRPM is computerised within a software system called ClientPro and has been received as generally satisfactory in 
effectiveness. Test feedback reports that requirements generation, prioritization, clarity and visibility were adequately supported within the formal process. Kamara and Anumba maintain that client requirements be:

- Precisely defined, with as little ambiguity as possible, and reflective of all the perspectives and priorities represented by the client body;

- Stated in a format that is solution-neutral (i.e. not based on any design concept that could serve as a solution to the client's problem) and which makes it easy to trace and correlate design decisions to the original intentions of the client.

ClientPro was evaluated by four industry practitioners and relatively rated low in areas such as the facilitation of communication among members of the processing team, the usefulness of the software to the overall construction process, and the ease to use the system (Kamara et al, 2002).

Other tools introduced for processing requirements is the Quality Function Deployments, which can be used for understanding and tracking requirements, and improving communication among product development team members (Kamara et al, 1999). This method is based on representing the requirements through matrixes as well as documenting. However, the use of QFD has been very modest in construction (Dikmen et al, 2005). Limitations of the use of QFD in construction as pointed out by Lima et al (2008) is being time consuming to process this information, particularly if the proportions of the matrix become very large, it is not easy to involve product development team members in the processing stages that are necessary to produce the matrix.

In another attempt to enhance the definition of the roles of employers in construction projects, the National Building Specifications (NBS), has adopted The Ministry of Justice's approach, which advocated a set of plain language questions that, as an employer, is expected to answer at each stage of a construction project. Key decisions such as whether to proceed to the next work stage or not will be made based upon the answers to these questions, each stage (from 0-7) have their own questions, according to what will be completed in each stage, which although are written in plain language and are easy to interpret and answer, they are not able to fully capture the employer's information requirements. Clearly there are many other important aspects that should be covered in order for the client to be able to deliver a complete and comprehensive requirement document for the construction team. According to PAS 1192-2:2013 (2013), the EIR should include information regarding 3 main aspects: Information Management, Commercial Management, and Competence Assessment, in addition to employer's requirements and the vision the employer has for the project.

\section{Purpose}

Despite the various research efforts, the specification of EIR is still underdeveloped. Indeed previous studies conducted by Graham (1983), Hudson et al. (1991), and Barrette et al. (1996) confirmed that due to complexities in identifying and conveying accurately employer's actual needs and requirements to the project's team and the immense magnitude of project information, project briefings may not truly reflect employer's information requirements.

In order to improve the specification of requirements, Kiviniemi (2005) suggested that is essential to develop IT tools to provide some degree of automation for requirements managements. However, 
the use of IT in that task poses important challenges, such as the difficulty of capturing both implicit and explicit requirements, maintaining information up to date, and storing different requirements from distinct stakeholders throughout the product development process (Leinonen and Huovila, 2001). An ontology-based approach has the potential to improve both requirements elicitation and management. Indeed, ontology as defined by Gruber (1995) is a specification of a conceptualization; that is that an ontology is a description of the concepts and relationships that can exist in the domain, this definition is consistent with the usage of ontology as set-of-concept-definitions, but more general. The relationships of the concepts existing in the domain is seen through the hierarchy of these concepts, where a domain is fragmented into classes and each class into sub classes until the instances are reached which are at the lowest rank of the hierarchy in the system.

The aim of this ongoing study is to develop an ontology-based, BIM enabled framework for Employer Information Requirements (OntEIR), for facilitating the identification and representation of requirements for construction and heritage projects. It seeks to provide a holistic OntEIR tool designed to assist employers to capture their requirements, in a language that is understandable and easy to interpret, which leads to improved quality information requirements in construction projects

EIR is the cornerstone for a successful project. The importance of OntEIR is derived from the fact, that defining adequate EIR is an important step in the forming of the HBEP, which will have the most influence on the project outcome. Another key reason for considering this system to be critical, is in its novelty in being addressed to main key players of the different disciplines involved in the BIM project, it seeks to provide answers and address questions and issues that will be of great importance for the formulating of the project programme for all disciplines.

\section{Methodology}

Well-defined EIRs will lead to the production of well written and comprehensive essential documents in the success of heritage projects. Due to the large amount of stakeholders and domain experts involved in the collaborative process of the project, in addition to the many types of heritage projects, ontology is considered the best option for this process due to what it offers in:

- Semantic heterogeneous description of requirements

- The ability to retrace requirements

- The ability to instantiate the framework to any construction project

The framework described in this study will have the aim to facilitate the identification, clarification, and representation of employer requirements in construction projects.

\section{Why ontology?}

In reference to Gruber's (1995) definition; ontology is a specification of conceptualization. Domain ontology specifies a generic of specific domain with all its relevant concepts, relationships and axioms given in a context.

Ontology defines a common vocabulary for researchers who need to share information in a domain. It includes machine-interpretable definitions of basic concepts in the domain and relations among them, Noy and McGuinness (2000), summarises the reasons we need Ontology in the following points 
- To share common understanding of the structure of information among people or software agents

- $\quad$ To enable reuse of domain knowledge

- $\quad$ To make domain assumptions explicit

- To separate domain knowledge from the operational knowledge

- To analyse domain knowledge

In other words, ontology is a formal representation of an abstract; it is a simplified view of a domain that describes the objects, concepts, and relationships between them.

In construction projects, and to ensure that projects are more employer-oriented; EIRs should be processed rigorously and coherently before the start of conceptual design. This should be done through a structured framework which provides for the definition, analysis, and translation of EIRs, into design specifications that are solutions neutral (Kamara et al, 1999)

To be able to form a clear an understandable brief by all part of the construction team, EIR should go through a process that begins with eliciting the EIRs in plain language, and converting them into constructional terms to be understood by all members of stakeholders.

The ontology introduced in the research will specify the concepts and relationships in the EIR domain. Ontology will facilitate the sharing of knowledge and understanding between relevant parties, by defining domain terminologies, vocabularies and relationships in the same way for all stakeholders. The Ontology introduced provides the common terms and vocabulary relations for modelling the EIR, where the ontology will lay the semantic understanding foundation.

In addition, the structuring and decomposition of requirements in a hierarchal way can facilitate the understanding of tracing requirements (Kott and Peasant, 1995, Ulrich and Eppinger, 2008) which will be tracked easier with the use of ontology. To evaluate attributes of criteria as well as compare requirements of each alternative in the system, it is necessary to use an appropriate data modelling and analysis methodology. In this system, the Ontology-based approach is adopted. This method is one of the fastest growing areas in the last several decades and it is used to support decision-making in challenges related to several disciplines (Chen \& Nugent, 2009).

Ontology provides a shared and reusable piece of knowledge about a specific domain, and has been applied in many fields, such as Semantic Web, e-commerce and information retrieval, etc. More and more researchers begin to pay attention to ontology research. Until now, many ontology editors have been developed to help domain experts to develop and manage ontology ( Li et al, 2005).

\section{OntEIR}

The first stage of the study was to develop a conceptual framework. The proposed conceptual framework identifies the predominant research issues, which have significant implications on EIR, works in the EIR and construction field such as PAS 1192-2:2013, RIBA plan of work, and the EIR guidance notes were studied as reference to the OntEIR framework, this framework seeks to draw together existing research and to provide a foundation for future work in this field. Within each of these categories, a series of attributes are examined. The framework is evaluated in a real-life 
situation, the findings and results of this evaluation is extracted and elicited and thoroughly documented, this will be used to improve and update the framework.

The initial framework developing process will go through a series of stages that attempt to define functions, classify functions, and develop function relations based on the literature review previously conducted.

1- Generating high-level goals:

Using mind mapping, the problem domain is elicited and analysed, the data visualized in the mind map is actually a representation of elicitation and analysis of requirements done with relevant stakeholders and domain experts via interviews. High level needs are formulated as result.

The visualization of the initial EIR framework is done through mind mapping that consists of all aspects of the EIR which are broken down to reach high level goals, this will help us in determining and generating requirements more clear and precise, and help the employer body in determining their more specific requirements and concerns regarding the project.

2- Requirement specification

After reached root goals in the goal hierarchy generated by the mind map, requirements are used where relevant. In case the requirements do not cover a root goal, then new requirements will have to be generated.

\section{3- Requirements validation}

Goals generated from mind map will be validated with relevant stakeholders and domain experts in the construction industry.

EIR is divided into two types of requirements: static requirements, and dynamic requirements, as shown in Fig 18.2

Figure 18.2: Heritage Employer Information Requirements

- Static requirements (include management information and technical information):

This type of requirements looks at the whole process as one system and delivers requirements in that sense, they are unchangeable through the different phases of the process, and contain definitions for terms that will be used during the process and in the different data drops that is specified in detail in the dynamic requirements. These requirements organise the whole process, and defines the standards and the guidelines that will have to be met, in addition to the technological issues of the BIM process

Static requirements will cover the following issues:

- First of all the employer should specify the different stages he would prefer the process to go through (data drops). 
- The employer should define the different levels of development, and levels of information, which will be delivered at the different data drops.

- Software platforms that will be used during the HBIM process including version numbers that will be used by the supply chain to deliver the project, including any particular constraints set by the employer on the size of model files.

- Standards, Protocols, and regulations to be used during the process.

- Coordination and clash detection

Management requirements will detail high-level roles and responsibilities, standards, data security, the key decision points and the information to be available at each one. Technical requirements will cover issues like information format and file types, the minimum Levels of Definition at each stage and the software platforms to be used for exchanging information.

- Dynamic requirements (which include the commercial information):

This set of requirements looks at the process as different data drops; each drop having its own set of requirements and information to be delivered, it includes details on the Client's strategic purpose, the defined deliverables and a competence assessment for those looking to tender the heritage project and demonstrate their ability to deliver the requirements of the EIR

These requirements are more specific to data drops, what is required by the project team to be delivering at each stage, who will be involved, and how will that be done, they will answer the major part of the plain language questions. These requirements include:

- Main outcome of the data drop

- Project requirements for each data drop

- Level of detail, and level of information (as defined in the management information) for each data drop

- Actors

- Standards and guidance needed

- Software formats to be used

- Security

The breaking down of the requirements to reach high level goals is the first step in specifying requirements, and helps the employer determine their more specific concerns regarding the project, as shown in Fig 18.3 below, which represents the visualization of the breaking down of the Data Drop 2 in the dynamic requirements of the EIR: 
After reaching the mind map that holds the necessary information: EIR domain knowledge, problem domain knowledge, solution domain knowledge, and stakeholder information, OntEIR is developed to create an ontology-based system for EIRs, which will create quality requirements in terms of consistency, completeness, correctness, traceability, and the ability to be instantiated to any project.

The approach for accomplishing has the ability to classify and prioritize the requirements, determine the relations between them and deliver them in terms understandable for the construction team, which is the reason behind using ontology as the method for capturing and processing EIR.

The approach for reaching the generic ontology Meta model for specifying EIR for construction projects include, (see Fig. 18.4):

- Elicitation of problem space

- Summarize the problem space in a set of high level needs

- Develop goal hierarchies for each need

- Formulate the requirements based on identified root goals

Figure 18.4: Domain ontology of construction projects

As part of the framework, a Meta model for specifying EIR is reached, the Meta model basically describes the components of the EIR processing model and the relation between the different classes in it; analysing, constructing, and developing the rules and constraints between them.

\section{Concluding remarks}

This ongoing and novel study of creating an ontology-based, BIM-enabled framework for defining EIRs will have potential in delivering a better defined, comprehensive and consistent EIR, on which the HBEP will build on. Above all, a clearer EIR will lead to a more successful heritage project.

The success of OntEIR is due to following characteristics:

- Stakeholder and expert contribution to the study assists in understanding the need in heritage projects, which leads to defining better requirements in OntEIR to bridge the gap between clients and execution in heritage projects;

- OntEIR is able to cover all aspects of a well and complete defined EIR as specified in PAS 1192:2, in a clear and understandable form for both the employer and the project team.

- Hierarchy and tractability offered by ontology will make it possible for OntEIR to be instantiated for different types of projects;

- OntEIR is able to clearly answer the plain language questions and requirements that are to be met before moving from one stage to the other; 
- OntEIR will assist employers defining clear and adequate requirements, and at the same time will be easy to be interpreted by the design team and translated into building terms, and thus create better HBEP;

- OntEIR saves time in specifying requirements for projects and gives excellent results in terms of quality and consistency. 


\section{References}

Barrett, P.S. and Stanley, C. (1999) Better Construction Briefing. Oxford: Blackwell Science.

Bruce M. and Cooper R. (2000). Creative product design: a practical guide to requirements capture management, Wiley \& Sons, Ltd, Chichester, UK

Chen, L. and Nugent, C. (2009) Ontology-based activity recognition in intelligent pervasive environments", . International Journal of Web Information Systems. 5 (410-430)

Dikmen, I., Birgonul, M.T. and Kiziltas, S. (2005) Strategic use of quality function deployment (QFD) in the construction industry. Building and Environment. 1 (245-255)

Earley, M. (2015) BIM Level 2 Standards for Business. Available from: http://www.bimmanager.net/

Employer's Information Requirements Guidance Notes (2013) . BIM Management for value, cost, and carbon improvement

Graham, P. (1983) Reading the Clients Mind. Building. 30 September, (22-30)

Gruber, T.R. (1995) Toward Principles for the Design of Ontologies Used for Knowledge Sharing. International Journal of Human Computer Studies. 43, 5/6 , (907-928).

Hudson, J., Gameson, R.N. and Murray, J.P. (1991) The use of computer systems to improve communication between clients and construction professionals during the briefing process. In: Barret, P. and Males, R., eds. (1991) Practice Management, New Perspectives for the Construction Prefession. London: Chapman \& Hall

Kamara, J. (1999) Client Requirments Processing for Concurrent Lifecycle Design and Construction. PhD Dessertation, University of Teesside.

Kamara, J., Anumba, C. and Evbuomwan, N. (2000) Establishing and processing client requirements a key aspect of concurrent engineering in construction. Engineering, Construction and Architectural Management. 7 (15-28),

Kamara, J.M., Anumba, C. and Evbuomwan, N. (2002) Capturing Client Requirements in Construction Projects. London: Thomas Telford Ltd

Kiviniemi, A. (2005) Requirements Management Interface to Building Product Models. PhD, Stanford University

Kott, A. and Peasant, J.L. (1995) Representation and Management of Requirements: the RAPID-WS project. Concurrent Engineering: Research and Applications. 2 (93-106)

Lee, C C T and Egbu, C (2005) Capturing client needs in refurbishment projects. In: Khosrowshahi, F (Ed.), 21st Annual ARCOM Conference, 7-9 September 2005, SOAS, University of London. Association of Researchers in Construction Management, Vol. 2, 865-74

Li, M., Du, X.Y., Wang, S.: Learning ontology from relational database. In: Proc. of the 4th International Conference on Machine Learning and Cybernetics, Guangzhou, China(2005 
Lima, P., Formoso, C., and Echeveste, M.(2008) Client Requirements Processing in Low-Income House-Building using Visual Displays and the House of Quality. . Manchester, Proceedings... , Manchester, UK: University of Salford. , 2008.

Noy, F. and McGuinness, D. (2000) Ontology Development 101: A Guide to Creating Your First Ontology. Stanford University

Ulrich, K.T. and Eppinger, S.D. (2008) Product Design and Development. 4th ed. New York: McGrawHill 